\title{
In Memoriam...George J. Hill, M.D., Ph.D.
}

\author{
Richard E. Gallagher
}

Published online: 16 April 2014

(C) Springer Science+Business Media New York 2014

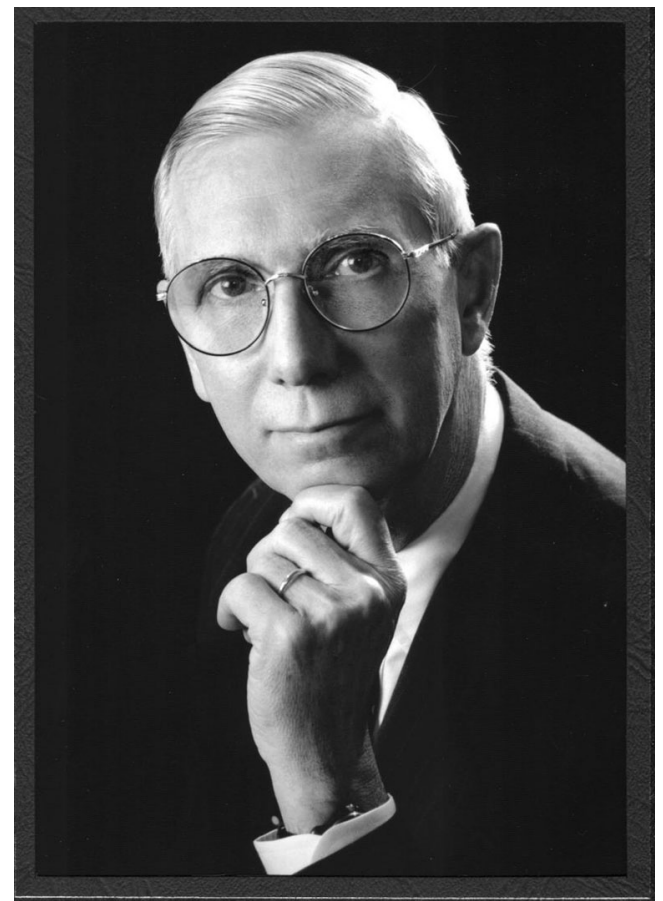

It is with a certain sense of sadness that we report the passing of a stalwart of the AACE, Dr. George J. Hill. George was known to many of us as a true scholar and a gentleman.

Dr. George J Hill was a long-time active member of the American Association of Cancer Education (AACE). He served in many of the leadership positions of the AACE including the presidency in 1986. Dr. Hill was the 1994 recipient of the Margaret Hay Edwards Medal for Lifetime Achievement in Cancer Education, the highest honor awarded by the AACE. One of his lasting contributions to the AACE was his recognition of the importance of preserving and making available to current and future members of the association its scholarly publications and the official leadership and management documents of its officers. To this end, he negotiated the placement of these documents in an official archive under the direction and management of the University Libraries of the University of Medicine and Dentistry of New Jersey, now merged with Rutgers University as Rutgers New Jersey Medical School. As George was fond of pointing out, such an archive not only provided access to the history of the AACE but is a font of wisdom that often can provide guidance and perspective for ongoing association management at any point in time. Dr Hill retired from the University of Medicine and Dentistry of New Jersey as Professor Emeritus in Surgery. In retirement, he continued to pursue his scholarly interest and love of history earning both a M.A. (Rutgers University, 1999) and a doctorate in 2005 (Drew University). Born in 1932, Dr. Hill died in September 2013.

R. E. Gallagher $(\bowtie)$

Department of Family Medicine \& Public Health Science, Wayne

State University Medical School, Detroit, MI, USA

e-mail: jceditor1@gmail.com 